\title{
Coronavirus Disease (Covid-19) in India - An Overview
}

\section{PK Kavitha*}

Department of Computer Applications, Kalasalingam Academy of Research and Education, India

*Corresponding Author: PK Kavitha, Department of Computer Applications, Kalasalingam Academy of Research and Education, India.
Received: March 30, 2020

Published: April 24, 2020

(c) All rights are reserved by PK Kavitha.

\begin{abstract}
Coronaviruses are a family of viruses that can cause illnesses such as the common cold, severe acute respiratory syndrome (SARS) and Middle East respiratory syndrome (MERS). In 2019, a new Coronavirus was identified as the cause of a disease outbreak that originated in China. After starting in China, Coronavirus is now spreading fast in many countries including India.

The virus is now known as the severe acute respiratory syndrome Coronavirus 2 (SARS-CoV-2). The disease it causes is called Coronavirus disease 2019 (COVID-19). COVID-19 is spreading fast across the globe, currently affecting 177 countries, with around 234000 patients and 10000 deaths as on $21^{\text {st }}$ March. It took around three months to reach first 100,000 patients, but the next 100,000 came in under two weeks.

In India, a total of 15,404 samples from 14,514 individuals have been tested for SARS-CoV2 as on 20th March 20206 PM IST. A total of 236 individuals have been confirmed positive among suspected patients and contacts of known patients. As on 21st March, four deaths have been reported in India due to COVID-19.

Cases of COVID-19 have been reported in a growing number of countries, including the U.S. Public health groups, such as the World Health Organization (WHO) and the U.S. Centers for Disease Control and Prevention (CDC), are monitoring the situation and posting updates on their websites. The World Health Organization called it a pandemic on March 11, 2020. COVID-19 was identified in Wuhan, China on December 31, 2019; the disease has spread across the world, affecting over 200,000 people in 166 countries and more than 8,700 deaths.
\end{abstract}

Keywords: Coronavirus Disease (Covid-19); India; World Health Organization (WHO)

\section{Background}

The name Coronavirus is derived from the Latin corona, meaning "crown" or "halo", that refers to the characteristic appearance reminiscent of a crown or a solar corona around the virus particles when viewed under two-dimensional transmission electron microscopy, due to the surface being covered in club-shaped protein spikes.

Coronaviruses are a group of related viruses that cause diseases in mammals and birds. In humans, Coronaviruses cause respiratory tract infections that can be mild, such as some cases of the common cold (among other possible causes, predominantly rhinoviruses), and others that can be lethal, such as SARS, MERS, and COVID-19. Symptoms in other species vary: in chickens, they cause an upper respiratory tract disease, while in cows and pigs they cause diarrhea. There are yet to be vaccines or antiviral drugs to prevent or treat human Coronavirus infections.

Coronaviruses constitute the subfamily Orthocoronavirinae, in the family Coronaviridae, order Nidovirales, and realm Riboviria. They are enveloped viruses with a positive-sense single- stranded RNA genome and a nucleocapsid of helical symmetry. The genome size of Coronaviruses ranges from approximately 27 to 34 kilo bases, the largest among known RNA viruses.

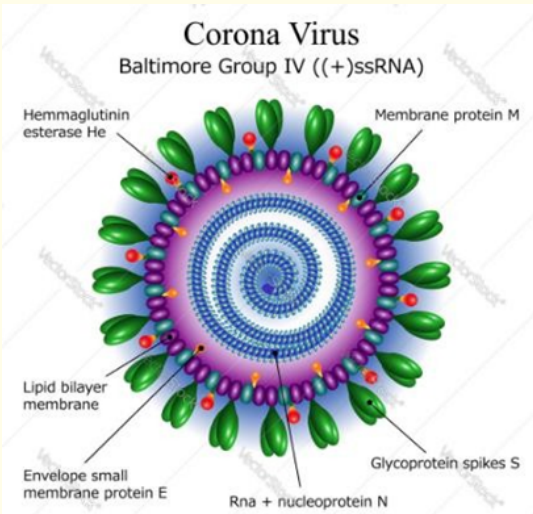

Figure 1: Coronavirus.

Most people infected with the COVID-19 virus will experience mild to moderate respiratory illness and recover without requiring special treatment. Older people and those with underlying medical problems like cardiovascular disease, diabetes, chronic respiratory disease, and cancer are more likely to develop serious illness.

\section{How it spreads}

Coronavirus disease spreads primarily through contact with an infected person when they cough or sneeze. It also spreads when 
a person touches a surface or objects that has the virus on it, and then touches their eyes, nose, or mouth.

To date there has been no information or evidence to suggest that the new Coronavirus could be transmitted by mosquitoes. This is a respiratory virus which spreads primarily through droplets generated when an infected person coughs or sneezes, or through droplets of saliva or discharge from the nose.

People of all ages can be infected by the new Coronavirus (2019-nCoV). Older people and people with pre-existing medical conditions such as asthma, diabetes, and heart disease appear to be more vulnerable to becoming severely ill with the virus.

Tens of thousands of new cases are being reported worldwide each day. However, it is thought health agencies may be unaware of many cases. It took 67 days from the first reported case to reach the first 100,000 cases, 11 days for the second 100,000 cases and just four days for the third 100,000 cases.

\section{Symptoms}

COVID-19 symptoms can range from very mild to severe. Some people have no symptoms. Some people have the following symptoms of COVID-19:

- Fever

- Dry Cough

- Nasal Congestion

- $\quad$ Sore throat

- Diarrhea

- Fatigue

- Difficulty breathing or Shortness of breath

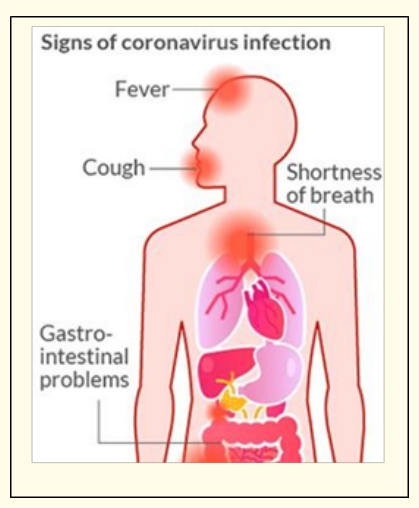

Figure

These above symptoms may appear from 1 to 14 days before developing symptoms. Older people and people with other medical conditions such as heart disease, diabetes or asthma may be more exposed to becoming severely ill.

\section{Typical symptoms}

COVID-19 typically causes flu-like symptoms including a fever and cough. In some patients - particularly the elderly and others with other chronic health conditions - these symptoms can devel-

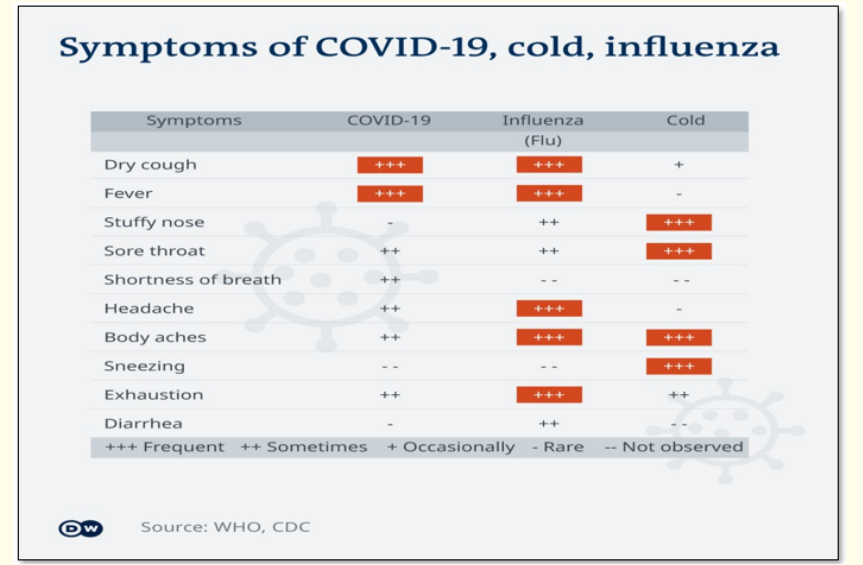

Figure 2: Symptoms of COVID-19.

op into pneumonia, with chest tightness, chest pain, and shortness of breath. It seems to start with a fever, followed by a dry cough. After a week, it can lead to shortness of breath, with about $20 \%$ of patients requiring hospital treatment.

Notably, the COVID-19 infection rarely seems to cause a runny nose, sneezing, or sore throat (these symptoms have been observed in only about $5 \%$ of patients). Sore throat, sneezing, and stuffy nose are most often signs of a cold. $80 \%$ of cases are mild.

Based on all 72,314 cases of COVID-19 confirmed, suspected, and asymptomatic cases in China as of February 11, a paper by the Chinese CCDC released on February 17 and published in the Chinese Journal of Epidemiology has found that:

- $\quad 80.9 \%$ of infections are mild (with flu-like symptoms) and can recover at home.

- $13.8 \%$ are severe, developing severe diseases including pneumonia and shortness of breath.

- $\quad 4.7 \%$ as critical and can include: respiratory failure, septic shock, and multi-organ failure.

- In about $2 \%$ of reported cases the virus is fatal.

- $\quad$ Risk of death increases the older you are.

- Relatively few cases are seen among children.

Prevention

To date, there is no specific medicine recommended to prevent or treat the new Coronavirus. From the evidence so far, the COVID-19 virus can be transmitted in ALL AREAS, including areas with hot and humid weather. There is some limited evidence that regularly rinsing nose with saline can help people recover more quickly from the common cold. However, regularly rinsing the nose has not been shown to prevent respiratory infections.

Our normal body temperature remains around $36.5^{\circ} \mathrm{C}$ to $37^{\circ} \mathrm{C}$, regardless of the temperature of bath or shower. Actually, taking a hot bath with extremely hot water can be harmful, as it can burn us.

To prevent infection and to slow transmission of COVID-19, do the following: 
- Practice physical distancing by avoiding unnecessary travel and staying away from large groups of people.

- Refrain from smoking and other activities that weaken the lungs.

- Maintain at least 1 meter distance between you and people coughing or sneezing.

- Wash your hands regularly with soap and water, or clean them with alcohol-based hand rub.

- Avoid touching your face.

- Cover your mouth and nose when coughing or sneezing.

- Stay home if you feel unwell.

World health organization (WHO)

WHO advises people of all ages to take steps to protect themselves from the virus. The virus is so new and different that it needs its own vaccine. Researchers are trying to develop a vaccine against 2019- nCoV and WHO is supporting their efforts. Although these vaccines are not effective against 2019- $\mathrm{nCoV}$, vaccination against respiratory illnesses is highly recommended to protect your health.

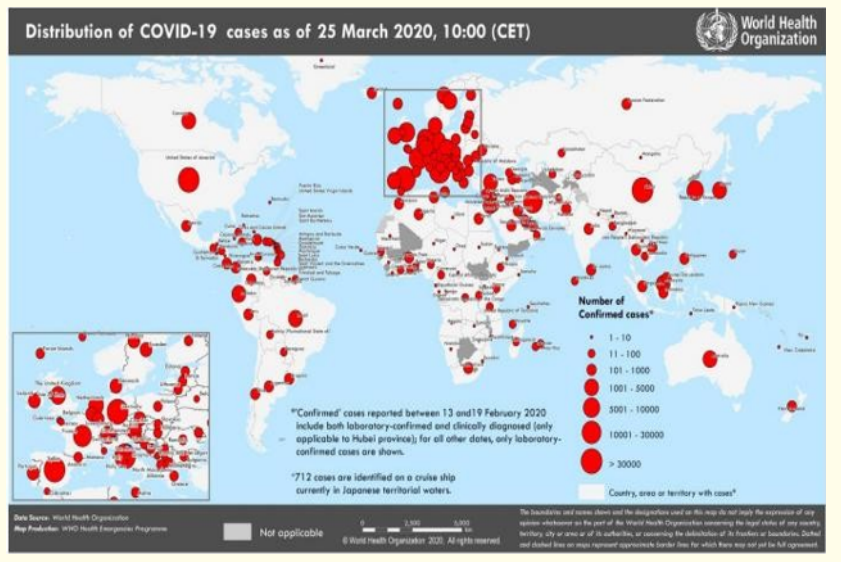

Figure 3: Distribution of Covid-19 till 25th March.

Vaccines against pneumonia, such as pneumococcal vaccine and Haemophilus influenza type B (Hib) vaccine, do not provide protection against the new Coronavirus. However, those infected with the virus should receive appropriate care to relieve and treat symptoms, and those with severe illness should receive optimized supportive care. Some specific treatments are under investigation and will be tested through clinical trials.

How long do symptoms last?

Using available preliminary data, the Report of the WHO-China Joint Mission published on February 28 by WHO, which is based on 55,924 laboratory confirmed cases, observed the following median time from symptoms onset to clinical recovery:

- Mild cases: approximately 2 weeks.

- Severe or critical disease: 3 - 6 weeks.

- Time from onset to the development of severe disease (including hypoxia): 1 week.
Among patients who have died, the time from symptom onset to outcome ranges from 2 - 8 weeks.

\section{Precautions and actions taken against corona in India}

Despite being the world's second most populous country, with more than 1.3 billion people, the nation has reported three deaths and around 150 cases, giving rise to questions about why the virus has not spread as rapidly as elsewhere.

For some, the answer is the fast action that India's government took as the virus spread from China to many parts of the world. And if the relatively low number of cases continues, it could make the nation a blueprint for others seeking to limit the impact.

"Apart from ensuring the safe return of hundreds of Indians from China, Iran and other countries, the Indian government has taken decisive measures to contain community spread," said Sriram Gutta, Head of Community Development, India and South Asia at the World Economic Forum. "While these measures will have short-term economic impact, they will ensure the safety and welfare of Indians".

\section{Janata curfew (People's curfew)}

Janata curfew was an effort to fight Coronavirus spread, introduced by the Prime Minister of India, Narendra Modi, in the wake of the 2020 Coronavirus pandemic in India. On $19^{\text {th }}$ March, 2020, the Prime Minister implored all citizens of India to observe a self-imposed 'curfew' from 7 am to $9 \mathrm{pm}$ IST on Sunday, 22 March 2020 to help reduce community spreading of Coronavirus disease in India. On 24 ${ }^{\text {th }}$ March, the prime minister announced that India go under 'total lock- down' for the next 21 days.

\section{Nationwide lockdown in India}

India's Prime Minister Narendra Modi has imposed a nationwide lockdown in an attempt to slow the spread of the Coronavirus. The restrictions came into force at midnight local time (18:30 GMT) and will be enforced for 21 days from March $24^{\text {th }}$ to April $14^{\text {th }}$. "There will be a total ban on venturing out of your homes," Mr Modi said in a televised address.

He appealed for people not to panic - but crowds quickly mobbed stores in the capital, Delhi, and other cities. The new measures follow a sharp increase in cases in recent days. There have been 519 confirmed cases across India and 10 reported deaths. India - which has a population of $1.3 \mathrm{bn}$ joins a growing list of countries that have imposed similar measures. Nearly 400,000 people have tested positive for the virus worldwide, and around 17,000 have died.

Some states have taken further precautions like the shutdown of Metro Trains, Suburban trains, Buses, Trams and Monorail services. Tamil Nadu will not allow visitors in jails during the Janata curfew, nor fishing is allowed. Only employees that work for essential services are allowed to board local trains in Mumbai, and the rail service has been cut back by a lot causing cancellation of more than 3,700 trains, these actions will start when the curfew takes effect however will end on March $31^{\text {st. }}$. 
In the case of Telangana, while supporting the Prime Minister's Janata curfew call, the Chief Minister of Telangana, K. Chandrashekar Rao appealed to the people of Telangana to stay indoors for $24 \mathrm{hrs}$ from 6 am on Sunday (22-03-2020) in order to contain the possible spread of Coronavirus.

Isolation, quarantine and social distancing

The COVID-19 infection rate in India remains low relative to population size. Some credit fast government action to quarantine people and shut borders. Response is "impressive" says the World Health Organization. But officials are still preparing for broader outbreak and community transmission.

Isolation and quarantine help protect the public by preventing exposure to people who have or may have a contagious disease:

- Isolation: Separates sick people with a contagious disease from people who are not sick.

- Quarantine: Separates and restricts the movement of people who were exposed to a contagious disease to see if they become sick.

- Social Distancing or physical distancing: Is a set of nonpharmaceutical interventions or measures taken to prevent the spread of a contagious disease by maintaining a physical distance between people and reducing the number of times people come into close contact with each other.

Phone helplines

A "novel Coronavirus" landing page on the Ministry of Health's website gives the numbers of phone help lines, as well as detailed advice and guidelines. Actions like these have been lauded by the World Health Organization (WHO), which is leading the global charge against the virus. Countries across the world are implementing several safety measures to curb the spread of the virus. Among several measures to stop the spread of Coronavirus in India, the health ministry has set up Coronavirus Helpline Numbers in India for all states and Union Territories (UT).

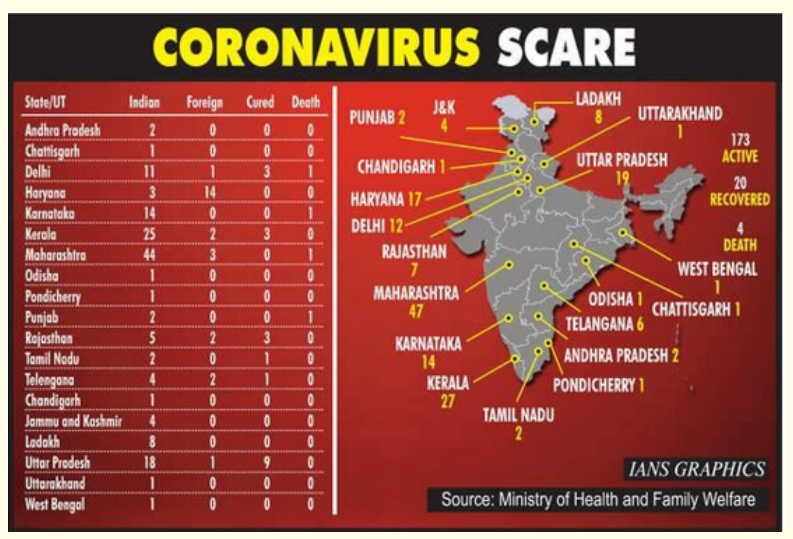

Figure 4: Distribution of Covid-19 in India ( $1^{\text {st }}$ stage).

Prime Minister Narendra Modi's government was quick to recommend residents avoid or postpone mass gatherings until the virus is contained. The Ministry of External Affairs postponed the Indian cricket league and state authorities are shutting schools, gyms

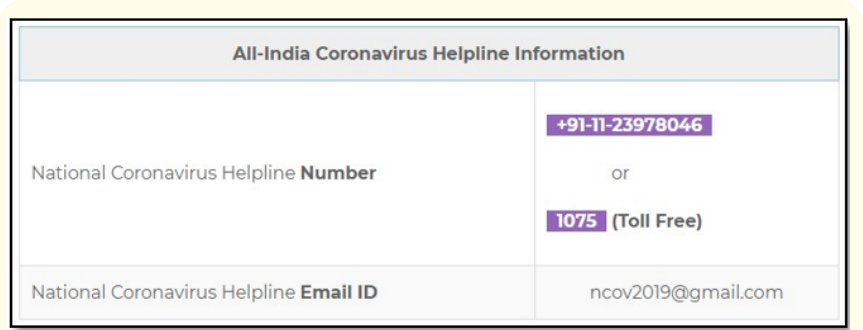

Figure 5: Helpline number and Email-ID.

and swimming pools in the worst-hit regions. Such responses are "good and impressive," according to the WHO. "India is doing quite well," said the WHO Representative, Henk Bekedam.

Even so, the nation still faces many of the same challenges as other countries, including limiting unauthorized gatherings and debunking fake health messages circulating on social media. The global economic impact will be hard to avoid, with the United Nations' trade and development agency predicting the slowdown in the global economy caused by the Coronavirus outbreak is likely to cost at least $\$ 1$ trillion.

The Public Health department of Maharashtra on said that consuming more garlic, curry leaves or cow's urine would neither treat nor prevent Coronavirus infection. Instead, they urged people to practice good hygiene, contain coughs and sneezes and eat nutritious food.

The Director-General of the Indian Council of Medical Research Balram Bhargava said that community transmission of COVID-19 has not yet occurred in India, meaning people who contracted the virus did so from a known source. Even so, officials are preparing for it to happen, with private laboratories authorized to test for the virus, freeing up more capacity for diagnosis and detection. Restaurants are also shutting, with the National Restaurants Association advising members to close at least until 31 March.

On $11^{\text {th }}$ March 2020, WHO declared Novel Coronavirus Disease (COVID-19) outbreak as a pandemic and reiterated the call for countries to take immediate actions and scale up response to treat, detect and reduce transmission to save people's lives.

The spread of Coronavirus in India as of March 19. India has tested some 14,175 people from 13,285 individuals as of March 19, Very small number compared to the possible threat of contagion in a country of 1.3 billion people. India has confirmed three Coronavirus deaths so far. India has suspended "all existing visas, except diplomatic, official, UN/international organizations, employment, project visas" until April 15.

On $24^{\text {th }}$ March 2020, the Prime Minister announced a 21-day nationwide lockdown: "In order to protect the country, and each of its citizens, from midnight tonight, a complete ban is being imposed on people from stepping out of their homes".

As of $29^{\text {th }}$ March 2020 (10:00 AM), according to the Ministry of Health and Family Welfare (MoHFW), a total of 979 COVID-19 cases 


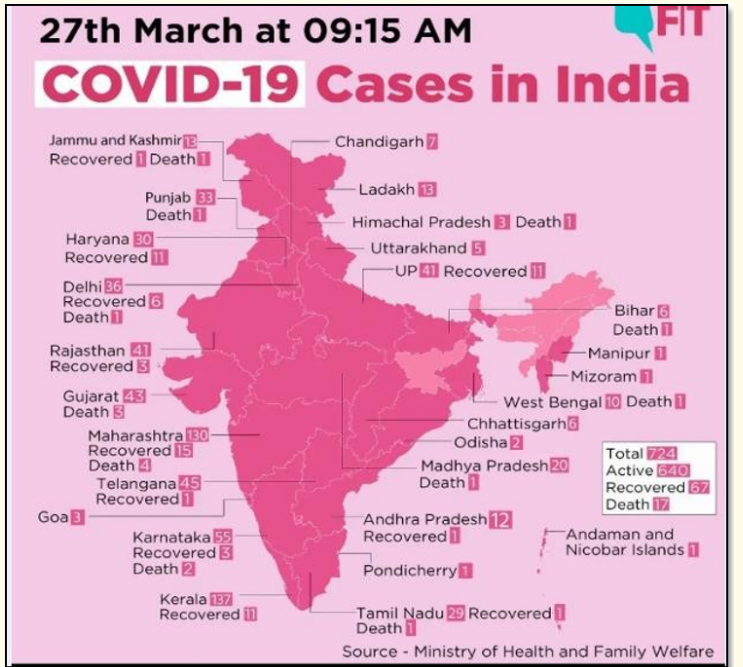

Figure 6: COVID-19 Cases in India till 27 $7^{\text {th }}$ March.

(931 Indians and 48 foreign nationals) have been reported in 27 states/union territories. These include 86 who have been cured and discharged, 1 who has migrated and 25 deaths. Hospital isolation of all confirmed cases, tracing and home quarantine of the contacts is ongoing.

\section{Medical arrangements in India}

When the Wuhan Virus first made serious headlines, the Indian government moved in quickly with the Indo-Tibetan Border Police (ITBP) establishing a 600-bed hospital outside Delhi while the Armed Forces Medical Centre began to manage an emergency medical centre in Haryana. Entry of foreigners was suspended, land borders sealed and later all flights stopped. Stranded Indians were retrieved by other Indians, including those in Wuhan and other parts of China, and from Iran and Italy as well. Many of those who themselves have access to the best medical facilities that money can buy in India and abroad have sniggered at the state of medical health facilities in the country.

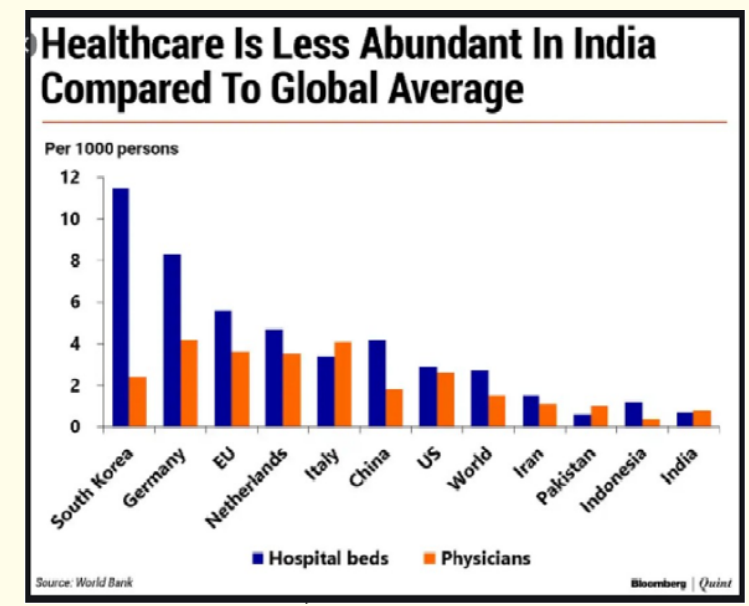

Figure 7: Healthcare facilities in India compared to other countries.

It is true that Indian medical arrangements are inadequate despite many state-of-the-art facilities. Even so, population pressure is immense not just in numbers but also in density. Inevitably, there are some snide comparisons to what Prime Minister Modi said in his speech in comparison to what the Canadian Prime Minister Justin Trudeau said in his in Canada. Canada is a country of 37 million people, while India has 1.3 billion. The Canadian GDP per capita is $\$ 46,213$, while Indian GDP is $\$ 2,044$. Canadians live in a land that is three times larger than Indians. They have just one friendly neighbor who protects them.

This situation did not come about in the last few years. If at all, it has improved for the common Indian through the Ayushman Bharat national health protection scheme, but no-one disputes that we have a long way to go. The advent of Covid19, or Wuhan virus, made India adopts a preemptive approach as much as possible thanks to the commendable selfless contribution from Indian doctors and the larger Indian medical and health community. For India, given our resources, limiting the damage will be a victory.

Coronavirus testing labs in India

The Coronavirus testing labs in Delhi are located at All India Institute of Medical Sciences and the National Centre for Disease Control. The Delhi government has authorized the below list of hospitals to collect samples for testing:

- Sanjay Gandhi Memorial

- Baba Saheb Amebedkar

- Lal Bahadur Shastri

- Babu Jagjivan Ram

- Chacha Nehru Bal Chikitsalaya

- Hindu Rao.

List of $\mathbf{5 2}$ testing centres for coronavirus in India

If you or anyone you know is suspected of COVID-19, one should go and get tested irrespective. The test is free and involves sampling of various bodily fluids. Here is the list of the 52 governmentdesignated laboratories all over India, according to Indian Council of Medical Research (ICMR):

\section{Andhra Pradesh}

- Sri Venkateswara Institute of Medical Sciences, Tirupati.

- Andhra Medical College, Visakhapatnam, Andhra Pradesh.

2. Andaman and Nicobar Islands

- GMC, Anantapur, AP.

- Regional Medical Research Centre, Port Blair, Andaman and Nicobar.

\section{Assam}

- Gauhati Medical College, Guwahati

- Regional Medical Research Center, Dibrugarh

4. Bihar

- Rajendra Memorial Research Institute of Medical Sciences, Patna

5. Chandigarh

- Post Graduate Institute of Medical Education \& Research, Chandigarh

\section{Chhattisgarh}

- $\quad$ All India Institute Medical Sciences, Raipur

7. Delhi-NCT

- $\quad$ All India Institute Medical Sciences, Delhi

- $\quad$ National Centre for Disease Control, Delhi 


\section{Gujarat}

- BJ Medical College, Ahmedabad

- M.P. Shah Government Medical College, Jamnagar

9. Haryana

- Pt. B.D. Sharma Post Graduate Inst. of Med. Sciences, Rohtak, Haryana

- BPS Govt Medical College, Sonipat

\section{Himachal Pradesh}

- Indira Gandhi Medical College, Shimla, Himachal Pradesh

- Dr. Rajendra Prasad Govt. Med. College, Kangra, Tanda, HP

11. Jammu and Kashmir

- Sher-e-Kashmir Institute of Medical Sciences, Srinagar

- Government Medical College, Jammu

12. Jharkhand

- MGM Medical College, Jamshedpur

\section{Karnataka}

- Bangalore Medical College \& Research Institute, Bangalore

- National Institute of Virology Field Unit Bangalore

- Mysore Medical College \& Research Institute, Mysore

- Hassan Inst. of Med. Sciences, Hassan, Karnataka

- Shimoga Inst. of Med. Sciences, Shivamogga, Karnataka

14. Kerala

- National Institute of Virology Field Unit, Kerala

- Govt. Medical College, Thriuvananthapuram, Kerala

- Govt. Medical College, Kozhikhode, Kerala

15. Madhya Pradesh

- All India Institute Medical Sciences, Bhopal

- National Institute of Research in Tribal Health (NIRTH), Jabalpur

16. Meghalaya

- NEIGRI of Health and Medical Sciences, Shillong, Meghalaya

17. Maharashtra

- Indira Gandhi Government Medical College, Nagpur

- Kasturba Hospital for Infectious Diseases, Mumbai

18. Manipur

- J N Inst. of Med. Sciences Hospital, Imphal-East, Manipur 19. Odisha

- Regional Medical Research Center, Bhubaneswar

20. Puducherry

- Jawaharlal Institute of Postgraduate Medical Education \& Research, Puducherry

21. Punjab

- Government Medical College, Patiala, Punjab

- Government Medical College, Amritsar

22. Rajasthan

- Sawai Man Singh, Jaipur

- Dr. S.N Medical College, Jodhpur

- Jhalawar Medical College, Jhalawar, Rajasthan

- $\quad$ SP Med. College, Bikaner, Rajasthan

23. Tamil Nadu

- King's Institute of Preventive Medicine \& Research, Chennai

- Government Medical College, Theni
24. Tripura

- Government Medical College, Agartala

25. Telangana

- Gandhi Medical College, Secunderabad

26. Uttar Pradesh

- King's George Medical University, Lucknow

- Institute of Medical Sciences, Banaras Hindu University, Varanasi

- Jawaharlal Nehru Medical College, Aligarh

27. Uttarakhand

- Government Medical College, Haldwani

\section{West Bengal}

- National Institute of Cholera and Enteric Diseases, Kolkata

- IPGMER, Kolkata

Indian Railways is exploring the feasibility of converting its coaches into isolation wards if the COVID-19 crisis deepens in the country, but there would challenges, according to Railways sources. That the trains are mobile, have a broad reach, have toilets, can be put along stations and can reach nook and corner of the country, make it an idea worth considering [1-19].

\section{Conclusion}

We still do not know when, where and how this horror will end. There is one thing however that the rest of the world must ensure that there is international accountability for this criminal act. If the world lets the pandemic linger, if we let this kind of activity happen long enough or frequently enough, society collectively will accept it as the new normal. As it is, it appears that this man-made disaster is also nature's revenge for all the ravages inflicted by mankind on mother Earth. Can we afford this and hope to survive? No, we will not unless we step back, pause and seriously look at the way we live and make some changes. Now is not the time to play politics; now is the time to hunker down, show resilience and fight this battle.

We have an opportunity to make an impact on our older adult patients now, as this pandemic continues to unfold. Above all, clinical researchers need to continue working - to help as many people as possible through the crisis.

\section{Bibliography}

1. Zhou P., et al. "A pneumonia outbreak associated with a new coronavirus of probable bat origin". Nature 579.7798 (2020): 270-273.

2. Phylogenetic analysis. Phylogenetic analysis of nCoV-2019 genomes (2020).

3. The Novel Coronavirus Pneumonia Emergency Response Epidemiology Team. "The Epidemiological Characteristics of an Outbreak of 2019 Novel Coronavirus Diseases (COVID-19) China, 2020". China CDC Weekly 2.8 (2020): 113-122.

4. Patel A and Jernigan DB. "Initial public health response and interim clinical guidance for the 2019 novel coronavirus outbreak - United States, December 31, 2019-February 4, 2020". Morbidity and Mortality Weekly Report 69.5 (2020): 140-146. 
5. Heymann DL and Shindo N. "COVID-19: what is next for public health?” Lancet 395.10224 (2020): 542-545.

6. Li G and De Clercq E. "Therapeutic options for the 2019 novel coronavirus (2019- nCoV)". Nature Reviews Drug Discovery 19.3 (2020): 149-150.

7. Stockman LJ., et al. "SARS: systematic review of treatment effects”. PLoS Medicine 3.9 (2006): e343.

8. Dale Fisher and David Heymann. "Q\&A: The novel coronavirus outbreak causing COVID-19”. BMC Medicine 18 (2020): 57.

9. Coronavirus Disease (COVID-19). WHO (2019).

10. Wikipedia. Coronavirus.

11. Emergencies Diseases. Coronavirus disease (2019).

12. COVID-19: Day in Review.

13. Global research on coronavirus disease (COVID-19).

14. Wikipedia. Janata Curfew.

15. The Wuhan Virus.

16. This is how India is reacting to the coronavirus pandemic.

17. A look at Indian government response to coronavirus, so far, shows some quick reactions but not enough foresight.

18. What Does the Coronavirus Do to the Body?

19. Coronavirus pandemic: Tracking the global outbreak.

\section{Assets from publication with us}

- Prompt Acknowledgement after receiving the article

- Thorough Double blinded peer review

- Rapid Publication

- Issue of Publication Certificate

- High visibility of your Published work

Website: https://www.actascientific.com/

Submit Article: https://www.actascientific.com/submission.php Email us: editor@actascientific.com

Contact us: +919182824667 